\title{
Smoking and Health in the Americas
} A 1992 Report of the Surgeon General, in collaboration with the Pan American Health
Organization

Executive Summary

On 12 March 1992 US Surgeon General Antonia C Novello released the 1992 Surgeon General's report on smoking and health. The report, produced in collaboration with the Pan American Health Organisation (PAHO), is the 22nd Surgeon General's report on smoking and health, and the first to have an international focus. It deals with smoking and health in the Americas, paying particular attention to Latin America and the Caribbean.

The complete report contains 213 pages, 69 tables, and eight figures. The executive summary is reproduced below. The acknowledgments section has been omitted; it lists 11 editors, nine contributing authors, 44 reviewers, and 39 other contributors.

A form for ordering the complete report is reproduced below. The report is available in English and Spanish. Additional copies of the executive summary and a consumer oriented four page summary ("At a Glance") are availablein English and Spanish-from the Office on Smoking and Health, National Center for Chronic Disease Prevention and Health Promotion, Centers for Disease Control, 1600 Clifton Road, NE, Atlanta, Georgia 30333, USA (tel (1404) 4885705; fax (1404) 488 5939).

$P A H O$ is publishing a report entitled Tobacco or Health: Status in the Americas, 1992 (PAHO Scientific Publication No 536). It accompanies the 1992 Surgeon General's report and contains information available as of late 1990 on tobacco use, tobacco related disease, and tobacco-use prevention and control efforts for the Region of the Americas, excluding the United States. The PAHO report (approximately 360 pages in length) contains information on each country and other political entities in the region. It will be available from PAHO in mid-1992 from the Tobacco or Health Program, Pan American Health Organisation, 525 23rd Street, NW, Washington, DC 20037, USA (tel (1 202) 8613266 ; fax (1 202) 2235971 ). - ED

Feb 14, 1992

TO: The Honorable Thomas S. Foley Speaker of the House of Representatives Washington, D.C. 20515 and

The Honorable Dan Quayle

President of the Senate

Washington, D.C. 20510

It is my privilege to transmit to the Congress the 1992 Surgeon General's report on the health consequences of smoking as mandated by Section $8(a)$ of the Public Health Cigarette Smoking Act of 1969 (Pub. L. 91-222). The report was prepared by the Centers for Disease Control's Office on Smoking and Health in conjunction with the Pan American Health Organization.

The topic of this report, Smoking in the Americas, reflects a concern for the broader problems posed by tobacco consumption. The report explores the historical, social, economic, and regulatory aspects of smoking in the Western Hemisphere. It defines the current extent of tobacco control activities in the countries of the Americas and stresses the need for regional coordination and cooperation in our efforts to create a smoke-free society.

The countries of North America-the United States and Canada-are in the midst of a major epidemic of smoking-related disease, including cancer, heart disease, chronic obstructive lung disease, and adverse outcomes of pregnancy. The countries of Latin America and the Caribbean now show evidence of a rising prevalence of smoking, particularly among young people, and in the absence of efforts to decrease tobacco use, are likely to be swept by a similar epidemic.

I believe that we in the United States must provide leadership through continued efforts to control tobacco consumption and prevent the uptake of smoking by young people. In addition, I believe that we must participate fully in regional efforts to develop effective smoking-control programs.

$$
\begin{array}{r}
\text { Sincerely, } \\
\text { Louis W. Sullivan, M.D. } \\
\text { Secretary of Health and Human Services }
\end{array}
$$
Washington, DC 20201

\section{Foreword}

By the mid-1980s, an estimated 526,000 people in the Americas were dying each year of diseases that are directly attributable to smoking. The number continues to increase. Most of these deaths occur in Canada and the United States, where smoking has been a widespread, entrenched habit for over 60 years. However, approximately 100,000 deaths occur annually in the countries of Latin America and the Caribbean. We are in the unfortunate position of watching an epidemic-like the one we are currently living with in the United Statesbegin to gather momentum among our neighbors.

The determinants of smoking are complex. 
Many forces are brought to bear on the young person who is deciding whether or not to smoke. The current overall prevalence of smoking in a population-a general measure of its social acceptability-plays a large role. The frequency with which peers or role models smoke may be even more important. The current laws and regulations that govern smoking may influence the decision, as do the price of cigarettes and the ease with which they can be purchased. The extent to which tobacco products are advertised and the forms and mechanisms for tobacco promotion are also likely to have a major influence on a young person's decision. All of these combine in an intricate way to create a social norm; the individual decision is hardly an isolated and independent event.

Considerable gains have been made against smoking in Canada and the United States in recent years. As documented in previous Surgeon General's reports, the prevalence of smoking in the United States has been falling at a rate of approximately 0.5 percentage points per year. But millions continue to smoke, and the current rate of decline will not reduce smoking prevalence to the goal of 15 percent set for the year 2000. It is clear that the efforts under way in the United States and Canada are important in maintaining the momentum of smoking abatement, but it is equally clear that they are insufficient. More sectors of society must be brought into the nonsmoking coalition, and the tools at our disposal must be further strengthened.

Other countries of the Americas face different circumstances. For some, still in the process of economic development, the prevalence of smoking is still low, and the problem may have a lower priority than more acute public health concerns. For others, further along in their development, diseases associated with smoking are already major causes of death, and the prevalence of smoking is high among young people in urban areas. Overall, the impact of smoking-related illness is not yet as evident in the other countries of the Americas as in Canada and the United States. However, the high prevalence among young people in many of these countries is ominous. Each country must deal with its problem in its own political, economic, and cultural context. Nonetheless, the countries of the Americas face a common threat, even though they may be in differing stages of its evolution. A common approach, characterized by agreement on goals, objectives, and means, can benefit the entire region.

The Pan American Health Organization (PAHO) has taken significant steps to establish a forum for the exchange of ideas and for the development of a joint plan of action. As a regional branch of the World Health Organization, PAHO in turn takes part in an international forum for coordinated action against tobacco. The individual decision to smoke-both now and in the future-will ultimately be influenced by these efforts of the global community.

This Surgeon General's report is the twenty-second in a series that was inaugurated in 1964 and mandated by law in 1969. The current report looks at the place of smoking in the societies of the Americas and at the current efforts to prevent and control tobacco use. It is perhaps best viewed as a planning document, a portrayal of the current situation in the Americas that will provide the basis for a concerted approach to future prevention strategies.

\section{James O. Mason, M.D., Dr.P.H. Assistant Secretary for Health, Public Health Service}

William L. Roper, M.D., M.P.H. Director, Centers for Disease Control

\section{Preface}

This 1992 report of the Surgeon General, Smoking and Health in the Americas, is the second on smoking and health during my tenure as Surgeon General. Over the years, the reports have systematically examined the effect of smoking on human health: the biologic effects of substances in tobacco, the risks of disease, the susceptibility of target organs, the addictive nature of nicotine, and the evolving epidemiology of the problem. The reports summarize a massive amount of information that has accumulated on the untoward effects of tobacco use, now easily designated the single most important risk to human health in the United States. The 1990 report, The Health Benefits of Smoking Cessation, documented the positive impact of quitting and thus furthered the logical argument leading to a smoke-free society.

This report is a departure from its predecessors in that it treats the evidence against smoking as an underlying assumption. The issue for the future is how we will go about achieving a smoke-free society, and a consideration of smoking in the Americas is an early step in that direction. The report explores the historical, epidemiologic, economic, and social issues that surround tobacco use in the

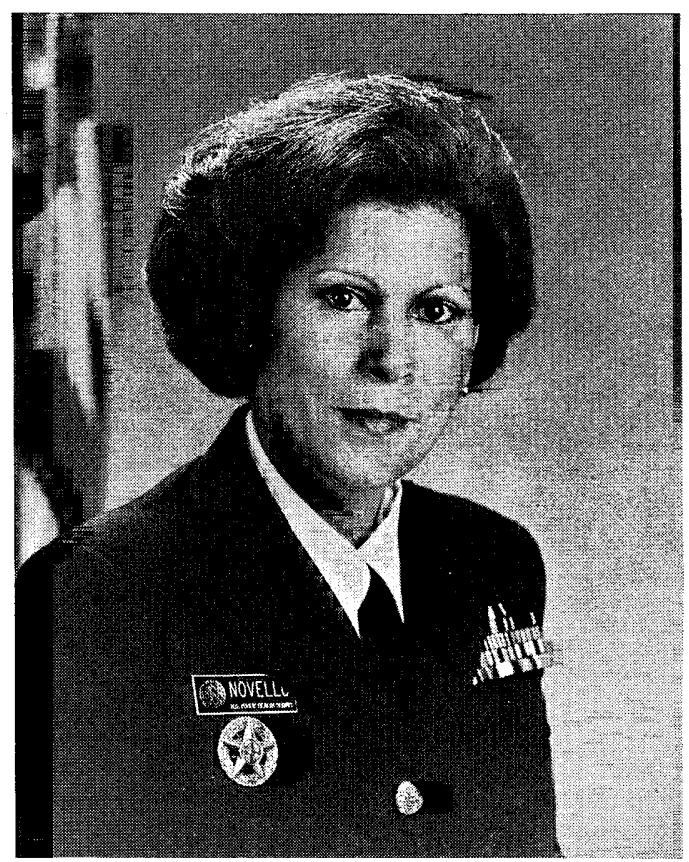

US Surgeon General Antonia C Novello 
Americas. It focuses on cultural antecedents and trends, on social and economic structure, and on the local, national, and regional efforts that are currently under way to control tobacco use.

One of the striking inferences to be drawn from the report is that the countries of the Americas occupy a continuum of consequences related to smoking. This continuum appears to be related to overall economic development. Countries that are further along the path of industrialization have gone through a period of high smoking prevalence and are now experiencing the incongruous combination of declining prevalence and increasing morbidity and mortality from smoking. Other countries, substantially along the path, are entering a period of high prevalence and may also be experiencing some of the disease and disability associated with smoking. Still others, less developed industrially, have low prevalences of smoking and relatively lower estimates for smoking-attributable mortality, but must contend with numerous other public health issues.

Not all countries fit easily into such a simple classification. Within countries, there is considerable diversity in the pace of industrialization, urbanization, and general development as well as in the manifestation of the effects of tobacco use. But the classification is useful in defining the pathway that all countries are likely to take. In the absence of coordinated action, the epidemic of tobacco use is likely to proceed according to a well-defined script: gradual adoption of the smoking habit, longterm entrenchment of tobacco use, and a major loss of human life.

The forces that create this script are complex and often difficult to untangle. One of the major findings of the report is the crucial role of surveillance in understanding the intricate interrelationship of the factors that influence smoking. The educational level of the population, for example, illustrates the complexity. Data from selected sources indicate that smoking is more prevalent among highly educated women than among less-educated women. One would think that increased education would be linked to a greater awareness of and concern about the health consequences of smoking, but this assumption appears incorrect. It may be that a higher education level, especially in developing countries, imparts, greater susceptibility to messages that promote positive associations with smoking. Only through systematic monitoring of smoking prevalence as well as of the knowledge, attitudes, and behaviors of the population can we appreciate the underlying reasons for the current epidemiologic configuration. Such appreciation, in turn, is the basis for a rational prevention and control program.

Another area in which surveillance is critical is in the monitoring of the tobacco sector of the economy. Such monitoring should include production, consumption, price structure, and taxation policy as well as advertising and promotion of tobacco products. The structure of the industry in any country will have important ramifications for the growth and "success" of the commodity. One of the fundamental paradoxes of market-oriented societies is that some entrepreneurs-even acting completely within the prescribed rules of business practice-will come into conflict with public health goals. The market structure of the tobacco industry constitutes a major threat to public health simply because the product is tobacco. In the tobacco industry, attempts to control a large market share, marketing to target groups, widespread use of innovative promotional techniques, and corporate growth, development, and consolidation-in short, the traditional elements of successful entrepreneurial activity-are ultimately inimical to the public health. Each country faces its own resolution of this paradox, but recognizing and monitoring it is fundamental to the prevention and control of tobacco use.

Most countries of the Americas have begun to face these complex issues. Several have taken major steps, others tentative ones, but all should recognize the crucial role of international coordination and cooperation. It is clear that although most countries can have significant impact on their own smokingrelated problems, the international community can become smoke-free only by acting in concert. The process is an arduous one that begins with multifaceted efforts to change social norms regarding smoking and that moves ultimately to a disappearance of demand for tobacco products. I hope that the current report will serve as an impetus for continuing activity in the control of smoking and for mobilization of international resources toward the goal of a smoke-free society.

Antonia C. Novello, M.D., M.P.H. Surgeon General

\section{Preface}

Diseases related to smoking are an important cause of premature deaths in the world, both in developed and developing countries. Eliminating smoking can do more to improve health and prolong life than any other measure in the field of preventive medicine.

Developing countries, including those of Latin America and the Caribbean, are not behind their neighbors in the north with regard to the tremendous growing problem of noncommunicable diseases related to tobacco consumption.

Over the last three decades, the countries of Latin America and the Caribbean have experienced important changes in their demographic, socioeconomic, and epidemiologic profiles. Increasing numbers of the older, more urban, and especially the poorer populations of the region, are dying of diseases related to lifestyle determinants. Consumption of tobacco is one of these harmful threats to the health and well-being of our populations.

Despite that, in most of the developing countries of our region, not enough attention has been given to generate actions and the kind of information needed for policy and program formulation with regard to tobacco control. It 
is also unfortunate that while the transnational conglomerates in control of almost all tobacco production and marketing have directed their efforts toward penetrating developing economies, many governments, given the urgent needs created by other health problems, and in some cases due to financial or economic reasons, consider tobacco control a low priority.

The United States Government and the Pan American Health Organization (PAHO) have been working in a joint effort to generate the information included in the Surgeon General's report, and the PAHO country report, which hopefully will bring more awareness and promote action against smoking in the region of the Americas.

Our collaboration with the Office of the Surgeon General has been highly satisfactory, and it will encourage the development of a regional network for implementing research and exchange of successful experiences in the control of tobacco addiction.

Carlyle Guerra de Macedo, M.D., M.P.H.

Director, Pan American Health Organization

\section{Contents}

Countries of the Americas

Notes on the Text

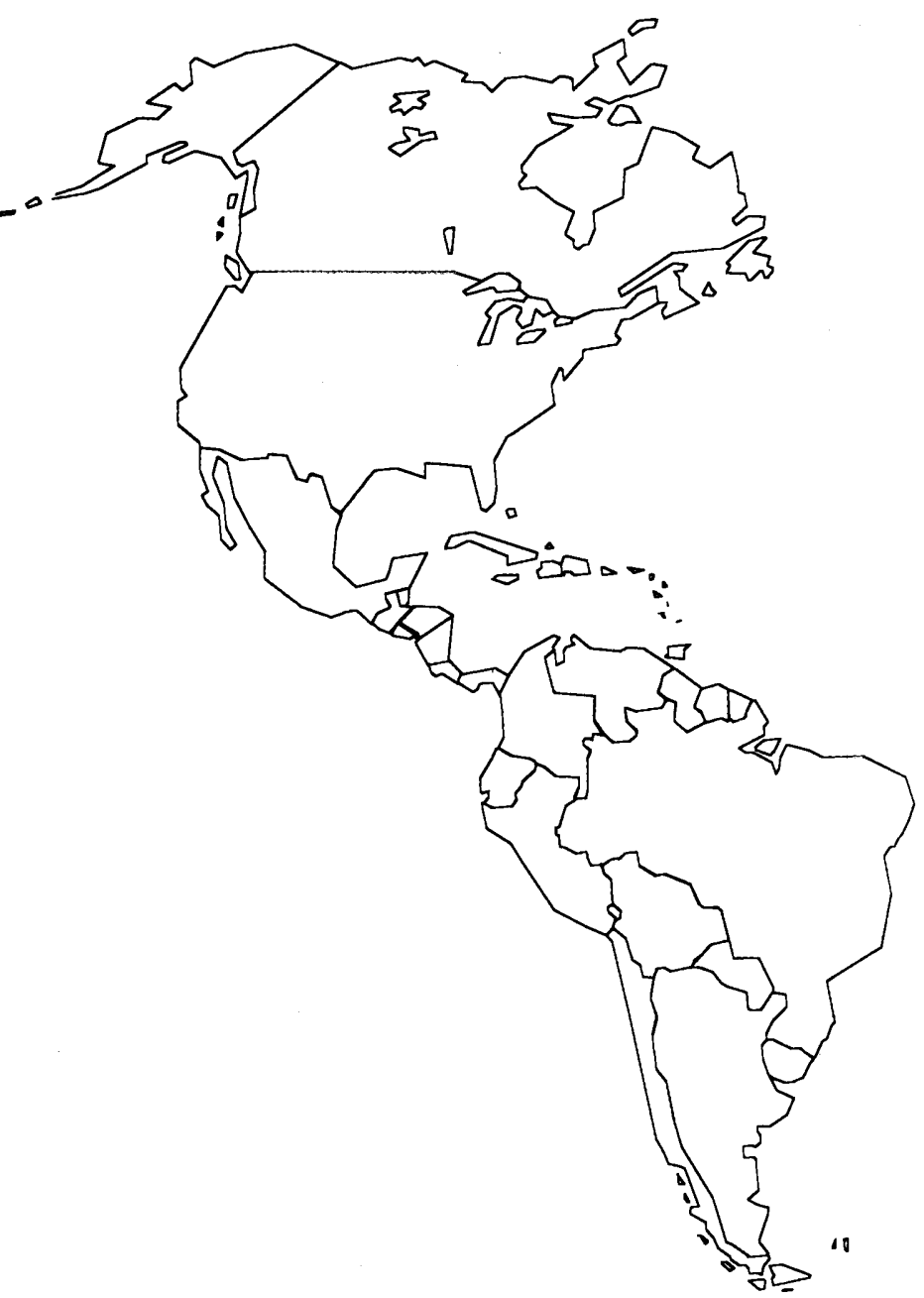

Chapter 1. Introduction, Summary, and Chapter Conclusions

Chapter 2. The Historical Context

Tobacco Use in Indigenous Societies

The Emergence of the Cigarette, 1492-1900

The Emergence of the Tobacco Companies, 1900 to the Present

Chapter 3. Prevalence and Mortality

Prevalence of Smoking in Latin America and the Caribbean

Smoking-Attributable Mortality in Latin America and the Caribbean

Chapter 4. Economics of Tobacco Consumption in the Americas

Economic Costs of the Health Effects of Smoking Economics of the Tobacco Industry

Chapter 5. Legislation to Control the Use of Tobacco in the Americas

Legislation to Control Production, Manufacture, Promotion, and Sales

Legislation to Change Smoking Behavior

The Impact of Antitobacco Legislation

Chapter 6. Status of Tobacco Prevention and Control Programs in the Americas

National Programs for Tobacco Control

Regional Activities for Tobacco Control in Latin America and the Caribbean

Elements of Prevention and Control Programs

List of Tables and Figures

Index

Countries of the Americas

$\begin{array}{cl}\text { Latin America } & \text { Caribbean } \\ \text { Andean Area } & \text { Anguilla } \\ \text { Bolivia } & \text { Antigua and Barbuda } \\ \text { Colombia } & \text { Bahamas } \\ \text { Ecuador } & \text { Barbados } \\ \text { Peru } & \text { Bermuda } \\ \text { Venezuela } & \text { British Virgin Islands } \\ \text { Southern Cone } & \text { Cayman Islands } \\ \text { Argentina } & \text { Dominica } \\ \text { Chile } & \text { French Guiana } \\ \text { Paraguay } & \text { Grenada } \\ \text { Uruguay } & \text { Guadeloupe } \\ \text { Brazil } & \text { Guyana } \\ \text { Central America } & \text { Jamaica } \\ \text { Belize } & \text { Martinique } \\ \text { Costa Rica } & \text { Montserrat } \\ \text { El Salvador } & \text { Netherlands Antilles } \\ \text { Guatemala } & \text { and Aruba } \\ \text { Honduras } & \text { Saint Kitts and Nevis } \\ \text { Nicaragua } & \text { Saint Lucia } \\ \text { Panama } & \text { Saint Vincent and } \\ \text { Mexico } & \text { the Grenadines } \\ \text { Latin Caribbean } & \text { Surinam } \\ \text { Cuba } & \text { Trinidad and Tobago } \\ \text { Dominican Republic } & \text { Turks and Caicos Islands } \\ \text { Haiti } & \text { Virgin Islands } \\ \text { Puerto Rico } & \\ & \text { North America } \\ & \text { Canada } \\ & \text { United States of America } \\ \end{array}$

Data in this report are almost exclusively presented by the above regions. In some instances, however, information is presented separately for the French overseas departments in the Americas (French Guiana, Guadeloupe, and Martinique) and the French territory Saint Pierre and Miquelon, which is in North America. Such instances are noted in the text.

The designations employed and the presentation of the material in this publication do not imply the 
expression of any opinion whatsoever on the part of the Secretariat of the Pan American Health Organization or the U.S. Department of Health and Human Services concerning the legal status of any country, territory, city, or area of its authorities, or concerning the delimitation of its frontiers or boundaries.

Chapter 1. Introduction, Summary, and Chapter Conclusions

Introduction

Development of the Report

Major Conclusions

Summary

Chapter Conclusions

Chapter 2. The Historical Context

Chapter 3. Prevalence and Mortality

Chapter 4. Economics of Tobacco Consumption in the Americas

Chapter 5. Legislation to Control the Use of Tobacco in the Americas

Chapter 6. Status of Tobacco Prevention and Control Programs in the Americas

\section{References}

\section{Introduction}

Recognition that the problems posed by personal risks are amenable to social solutions is an important contribution of modern public health. Each person makes choices, but such choices are shaped by social, economic, and environmental circumstances. On an even broader scale, national choices are made in a complex regional or global setting. This report attempts to place the personal risk of smoking in the Americas in the larger context and to underline both the heterogeneity and the interrelationships of nations.

Previous Surgeon General's reports have focused primarily, although not exclusively, on the epidemiologic, clinical, biologic, and pharmacologic aspects of smoking. With the twenty-fifth anniversary report (U.S. Department of Health and Human Services 1989), in which considerable attention was devoted to the social, economic, and legislative aspects of tobacco consumption, the need to place tobacco in a larger context was made apparent. Accordingly, this report now examines the broad issues that surround the production and consumption of tobacco in the Americas.

\section{Development of the Report}

The 1992 Surgeon General's report was prepared by the Office on Smoking and Health (OSH), National Center for Chronic Disease Prevention and Health Promotion, Centers for Disease Control, Public Health Service, U.S. Department of Health and Human Services, as part of the department's responsibility, under Public Law 91-222, to report current information on smoking and health to the U.S. Congress.

OSH, a World Health Organization Collaborating Center for Smoking and Health, works closely with the Pan American Health
Organization (PAHO). In the Regional Plan of Action for the Prevention and Control of Tobacco Use, PAHO responded to the thirtythird meeting (1988) of its Directing Council, which recommended that PAHO (1) collaborate with the countries of the Americas in the development of national programs for the prevention and control of smoking and (2) cooperate with member states and government and nongovernment centers and groups in identifying and mobilizing resources to contribute to this plan of action (PAHO 1989).

In February 1988, the Surgeon General, then C. Everett Koop, M.D., Sc.D., and the PAHO Director, Carlyle Guerra de Macedo, M.D., M.P.H., agreed to the development of a Surgeon General's report that focuses on smoking in the Americas. OSH and the Health of Adults Program of PAHO began work on this project.

OSH and PAHO presented the concept of a collaborative effort to attendees of the Fourth PAHO Subregional Workshop on the Control of Tobacco (Central America) in November 1988. Meetings of the Latin American Coordinating Committee on Smoking Control were also attended by OSH and PAHO staff in Santa Cruz, Bolivia (January 1989), and in Port of Spain, Trinidad and Tobago (March 1989).

Four experts on tobacco and health (from Brazil, Canada, Colombia, and Costa Rica) served on the Senior Editorial Board, and a collaborator was identified in each of the participating member states. In September 1989 , work began on the current report and on a country-by-country summary of the current status of tobacco prevention and control in the Americas, which PAHO is issuing as a companion document to this report (PAHO 1992).

The current report has been prepared from reviews written by experts in the historical, sociodemographic, epidemiologic, economic, legal, and public health aspects of smoking in the Americas. In addition to standard bibliographic sources, the report uses data supplied by the U.S. Department of Agriculture, the Centers for Disease Control, The World Bank, the World Health Organization, the Economic Commission for Latin America and the Caribbean, the Caribbean Community Secretariat, the Latin American Center on Demography, the International Union Against Cancer, the International Organization of Consumers Unions, the American Cancer Society, and the Latin American Coordinating Committee on Smoking Control.

In addition, this report uses information derived from a data collection instrument developed by PAHO (with technical assistance from $\mathrm{OSH}$ ) for the companion report on the current status of tobacco prevention and control in PAHO's member states. The data collection instrument requested current information on tobacco cultivation, cigarette consumption, legislation, taxation, government and non-government programs to control tobacco, tobacco-use surveys, and tobaccorelated disease impact. Detailed information from this data collection instrument was re- 
viewed at meetings in Caracas, Venezuela (February 1990), and Port of Spain, Trinidad and Tobago (March 1990), before incorporation into PAHO's country-by-country status report.

\section{Major Conclusions}

Five major conclusions have emerged from review of the complex factors affecting smoking in the Americas. The first two relate to the current size of the problem; the latter three, to current conditions that have an important influence on the prevention and control of tobacco use.

1. The prevalence of smoking in Latin America and the Caribbean is variable but reaches 50 percent or more among young people in some urban areas. Significant numbers of women have taken up smoking in recent years.

2. By 1985 , an estimated minimum of 526,000 smoking-attributable deaths were occurring yearly in the Americas; 100,000 of these deaths occurred in Latin America and the Caribbean.

3. In Latin America and the Caribbean, the current structure of the tobacco industry, which is dominated by transnational corporations, presents a formidable obstacle to smoking-control efforts.

4. The economic arguments for support of tobacco production are offset by the longterm economic effects of smoking-related disease.

5. Commitment to surveillance of tobaccorelated factors-such as prevalence of smoking; morbidity and mortality; knowledge, attitudes, and practices; tobacco consumption and production; and practices; tobacco consumption and production; and taxation and legislation-is crucial to the development of a systematic program for prevention and control of tobacco use.

\section{Summary}

The use of tobacco in the Americas long predates the European voyages of discovery. Among indigenous populations, tobacco was used primarily for the pharmacologic effects of high doses of nicotine, and it played an important role in shamanistic and other spiritual practices. Its growth as a cash crop began only after the European market was opened to tobacco in the early and mid-seventeenth century. During early colonial times, the focus for tobacco cultivation shifted from Latin America and the Caribbean to North America, where a light, mellow brand of tobacco was grown. Despite antitobacco movements, the popularity of tobacco increased dramatically after the U.S. Civil War, and by the early part of the twentieth century, the cigarette had emerged as the tobacco product of choice in the United States.

The first half of the twentieth century witnessed a spectacular increase in the popularity of cigarettes and in the growth of several major cigarette manufacturing companies in the United States. Interest in international expansion was minimal until after World War II. In the early 1950s, preliminary reports of the health effects of tobacco first appeared; these were followed in 1964 by the first report of the Surgeon General on the health effects of smoking (Public Health Service 1964). These events, which were accompanied by a downturn in U.S. tobacco consumption, ushered in a period of rapid international expansion by the tobacco companies. Their expansion into Latin America and the Caribbean was typified by a process of denationalization-that is, the abandonment of local government tobacco monopolies and the creation of subsidiaries by U.S. and British transnational tobacco corporations. The transnational companies were particularly successful in altering local demand by influencing consumer preferences. Local taste for dark tobacco in a variety of forms was largely replaced by demand for the long, filtered, light-tobacco cigarettes produced by the transnational companies.

During the 1980 s, several divergent forces influenced the consumption of tobacco in Latin America and the Caribbean. Changing demographs (primarily declining birth and death rates and an overall growth in the population), increasing urbanization, improving education, and the growing entry of women into the labor force-all expanded the potential market for tobacco. Although systematic surveillance evidence is lacking, an increased prevalence of smoking among young people, particularly women in urban areas, appears to have occurred during this period. A countervailing force, however, was the major economic downturn experienced by most countries of Latin America and the Caribbean during the 1980s. The result was that despite the increasing prevalence of smoking in some sectors of the population, overall consumption of tobacco declined. Unlike the decline in North America, however, the decline in Latin America and the Caribbean seems to have been based on income elasticity rather than on health concerns.

The health burden imposed by smoking in Latin America and the Caribbean is currently smaller than that in North America. A conservative estimate is that, by the mid-1980s, at least 526,000 deaths from smoking-related diseases were occurring annually in the Americas and that approximately 100,000 of these deaths occurred in Latin America and the Caribbean. Since the smoking epidemic is more recent, less widespread, and less entrenched in Latin America and the Caribbean than in North America, it may be thought of as less "mature" - that is, sufficient time has not yet elapsed for the cumulative effects of tobacco use to become manifest. Because health data from Latin American and Caribbean countries vary in consistency and comprehensiveness, establishing overall trends for morbidity and mortality is difficult. Nonetheless, the available evidence suggests an important contrast between North America on the one hand, and Latin America and the Caribbean on the other. In the United States and Canada, smoking-associated mortality is 
high and increasing because of high consumption levels in the past, but prevalence of smoking is declining. In Latin America and the Caribbean, prevalence of smoking is high in some sectors, but smoking-attributable mortality is still low compared with that for North America. This contrast augurs poorly for public health in Latin America and the Caribbean, unless action is taken.

The health costs of smoking are considerable. The U.S. population of civilian, noninstitutionalized persons aged 25 years or older who ever smoked cigarettes will incur lifetime excess medical care costs of $\$ 501$ billion. The estimated average lifetime medical costs for a smoker exceed those for a nonsmoker by over $\$ 6,000$. This excess is a weighted average of the costs incurred by all smokers, whether or not they develop smoking-related illness. For smokers who do develop such illnesses, the personal financial impact is much higher.

Available data do not permit a firm estimate for Latin America and the Caribbean. The estimate will probably vary with the health care structure of the country, but the burden is likely to increase with increasing development and industrialization. Nonetheless, early evidence suggests that smoking-prevention programs can be cost-effective under current economic circumstances.

The economics of the tobacco industry in the Americas are complex. Although tobacco had long been thought to be an inelastic commodity, it has been demonstrated to be both price and income elastic. Such elasticity renders tobacco use susceptible to control through taxation and other disincentives. Revenues from tobacco have been an important, though variable, source of funds for governments, but the case for promoting tobacco production on economic grounds is weak. Currently, only a few countries of Latin America and the Caribbean have economies that are largely dependent on tobacco production. The current economic picture, coupled with consumer responsiveness to income and price and the potential health hazards, has created a sufficient opportunity for tobacco control in Latin America and the Caribbean.

This opportunity is reflected, to some extent, in the fact that most countries of the Americas have legislation that controls tobacco use. Restrictions on advertising, the requirement of health warnings on tobacco products, limits on access to tobacco, and restrictions on public smoking have all been invoked. The legislative approach is not systematic, however, and in many countries, the programs have gaps. Furthermore, the extent to which such legislation is enforced is not fully known. Nonetheless, the pace of enactment suggests a growing awareness of the potential efficacy of the legislative approach.

Overall, the public health approach to tobacco control in Latin America and the Caribbean is variable. Many countries have adopted some elements of comprehensive control, including (in addition to legislation and taxation) the development of national co- alitions, the promotion of education and mediabased activities, and the development and refinement of surveillance systems. Few countries, however, have adopted the unified approach that characterizes, for example, the program in Canada.

The potential exists in the Americas for a strong, coordinated effort in smoking control at the local, national, and regional levels. The high prevalence of smoking that is emerging in many areas is a clear indicator of an approaching epidemic of smoking-related disease. The potential for decreasing consumption in Latin America and the Caribbean has been well demonstrated, albeit by the unfortunate mechanism of an economic downturn. The potential for a decline in smoking prevalence motivated by health concerns has been well demonstrated in North America. Furthermore, the importance of tobacco manufacturing and production to local economies is undergoing considerable scrutiny. Regional and international plans for tobacco control have been developed and are being implemented. For persons in the Americas in the coming years, the individual decision to smoke may well be made in an environment that is increasingly cognizant of the costs and hazards of smoking.

\section{Chapter Conclusions}

Following are the specific conclusions from each chapter in this report:

\section{Chapter 2. The Historical Context}

1. Tobacco has long played a role, chiefly as a feature of shamanistic practices, in the cultural and spiritual life of the indigenous populations of the Americas. This usage by a small group of initiates contrasts sharply with the widespread tobacco addiction of contemporary American societies.

2. During the latter half of the nineteenth century, amalgamation of major U.S. cigarette firms coincided with the emergence of the cigarette as the most popular tobacco product in the United States.

3. In Latin America and the Caribbean, through a process of denationalization and the formation of subsidiaries, a few transnational corporations now dominate the tobacco industry. The current structure of the industry presents a formidable obstacle to smoking-control efforts.

4. After rapid growth in per capita tobacco consumption in Latin America and the Caribbean during the 1960 s and 1970 s, a severe economic downturn during the 1980 s led to a decline in tobacco consumption. In the absence of countermeasures, an economic recovery is likely to instigate a resurgence of tobacco consumption.

\section{Chapter 3. Prevalence and Mortality}

1. Certain sociodemographic phenomenasuch as change in population structure, 
increasing urbanization, increased availability of education, and entry of women into the labor force-have increased the susceptibility of the population of Latin America and the Caribbean to smoking.

2. The lack of systematic surveillance information about the prevalence of smoking in most areas of Latin America and the Caribbean hinders comprehensive control efforts. Available information reflects a variety of survey methods, analytic schemes, and reporting formats.

3. Available data indicate that the median prevalence of smoking in Latin America and the Caribbean is 37 percent for men and 20 percent for women. Variation among countries is considerable, however, and smoking prevalence is 50 percent or more in some populations but less than 10 percent in others. In general, prevalence is highest in the urban areas of the moredeveloped countries and is higher among men than among women.

4. The initiation of smoking (as measured by the prevalence of smoking among persons 20 to 24 years of age) exceeds 30 percent in selected urban areas. Although systematic time series are not available, the data suggest that more recent cohorts (especially of women) in the urban areas of moredeveloped countries are adopting tobacco use at a higher rate than did their predecessors.

5. The smoking epidemic in Latin America and the Caribbean is not yet of long duration or high intensity, and the mortality burden imposed by smoking is smaller than that for North America. By 1985, an estimated minimum of 526,000 smoking-attributable deaths were occurring each year in all the countries of the Americas; 100,000 of these deaths occurred in Latin American and Caribbean countries.

6. The estimate of 526,000 deaths annually is conservative and is best viewed as the first point on a continuum of such estimates. However, it provides an order of magnitude for the number of smoking-attributable deaths in the Americas.

7. The time lag between the onset of smoking and the onset of smoking-attributable disease is foreboding. In North America, a high prevalence of smoking, now declining, has been followed by an increasing burden of smoking-attributable morbidity and mortality. In Latin America and the Caribbean, rising prevalence portends a major burden of smoking-attributable disease.

Chapter 4. Economics of Tobacco Consumption in the Americas

1. Because the health costs of tobacco consumption result from cumulative exposure, they are most pronounced in the economically developed countries of North America, which have had major long-term exposure. Since many countries of Latin America and the Caribbean are experi- encing an epidemiological transition, the economic impact of smoking is increasing.

2. The economic costs of smoking are a function of the economic, social, and demographic context of a given country. In the United States, estimated total lifetime excess medical care costs for smokers exceed those for nonsmokers by $\$ 501$ billion-an average of over $\$ 6,000$ per current or former smoker. Similar formal estimates for many Latin American and Caribbean countries are not available.

3. Evidence of the cost-effectiveness of smoking control and prevention programs has increased. In Brazil, for example, the cost of public information and personal smoking-cessation services is estimated at 0.2 to 2.0 percent of per capita gross national product (GNP) for each year of life gained; treatment for lung cancer costs 200 percent of per capita GNP per year of life gained.

4. In Latin America and the Caribbean, as GNP increases, cigarette consumption increases, particularly at lower income levels. This effect is attenuated at higher income levels.

5. Advertising tends to increase cigarette consumption, although the relationship is difficult to quantify precisely. Advertising restrictions are generally associated with declines in consumption and, hence, are an important component of tobacco-control programs.

6. The case for promoting increased tobacco production on economic grounds should be reconsidered. Although tobacco is typically a very profitable crop, much of the advantage of producing tobacco stems from the various subsidies, tariffs, and supply restrictions that support the high price of tobacco and provide economic rents for tobacco producers. Although the tobacco industry is a significant source of employment, production of alternative goods would generate similar levels of employment.

7. Increases in the price of cigarettes, which are a price-elastic commodity, cause decreases in smoking, particularly among adolescents. Excise taxes may thus be viewed as a public health measure to diminish morbidity and mortality, although the precise impact of taxes on smoking will be influenced by local economic factors.

Chapter 5. Legislation to Control the Use of Tobacco in the Americas

1. Legislation that affects the supply of and demand for tobacco is an effective mechanism for promoting public health goals for the control of tobacco use.

2. Although the direct effects of legislation are often difficult to specify because of interaction with a variety of other factors, there are numerous examples of an immediate change in tobacco consumption subsequent to the enactment of new laws and regulations. 
3. Most countries of the Americas have legislation that restricts cigarette advertising and promotion, requires health warnings on cigarette packages, restricts smoking in public places, and attempts to control smoking by young people. These laws and regulations, however, vary in their specific features. In many areas, the current level of enforcement is unknown.

Chapter 6. Status of Tobacco Prevention and Control Programs in the Americas

1. A basic governmental and nongovernmental infrastructure for the prevention and control of tobacco use is present in most countries of the Americas, although programs vary considerably in their degree of development.

2. The need is now recognized, and work is under way, for developing a comprehensive, systematic approach to the surveillance of tobacco-related factors in the Americas, including the prevalence of smoking; smoking-associated morbidity and mortality; knowledge, attitudes, and practices with regard to tobacco use; tobacco production and consumption; and taxation and legislation.

3. School-based educational programs about tobacco use are not yet a major feature of control activities in Latin America and the
Caribbean. The few evaluation studies reported indicate that such programs can be effective in preventing the initiation of tobacco use.

4. Cessation services in most countries of the Americas are often available through church and community organizations. Private and government-sponsored cessation programs are uncommon.

5. Media and public information activities for tobacco control are conducted in most countries of the Americas, but the extent of these activities and their effect on behavior are unknown.

\section{References}

PAN AMERICAN HEALTH ORGANIZATION. Regional plan of action for the prevention and control of the use of plan of action for the prevention and control of the use of tobacco. In: Final Reports of the 102 nd and 103rd Meetings of the PAHO Executive Committee, XXXIV Meeting of the
Directing Council of PAHO, XLI Meeting, WHO Regional Dommittee for the Americas. Official Document No. 232. Washington, DC: Pan American Health Organization, 198

PAN AMERICAN HEALTH ORGANIZATION. Tobacco or Health: Status in the Americas. Washington, DC: Pan American Health Organization. Scientific Publication No. 536, 1992.

PUBLIC HEALTH SERVICE. Smoking and Health. Report of the Advisory Committee to the Surgeon General of the Public Health Service. U.S. Department of Health, Education, and Welfare, Public Health Service. PHS Publication No. 1103,

1964. DEPARTMENT OF HEALTH AND HUMAN SERVICES. Reducing the Health Consequences of Smoking : 25 Years of Progress. A Report of the Surgeon General. U.S. Years of Progress. A Report of the Surgeon General. U.S. Department of Health and Human Services, Public Health Service, Centers for Disease Control, Center for Chronic Disease Prevention and Health Promotion, Office on Smoking
and Health. DHHS Publication No. (CDC) 89-8411, 1989.

\section{Superintendent of Documents Publications Order Form}

Order Processing Code

6209

$\square$ Yes, please send me the following:

Smoking and Health in the Americas

copies (English) S/N 017-001-00478-2 at \$12.00 each.

copies (Spanish) S/N 017-001-00479-7 at \$12.00 each.
To fax your orders:

(202)512-2250 . (International customers please add 25\%.) Prices include regular domestic postage and handling and are subject to change.

Please type or print

\begin{tabular}{l} 
(Company or personal name) \\
\hline (Additional address/attention line) \\
\hline (Street address) \\
\hline (City, state, ZIP Code) \\
\hline (Daytime phone including area code) \\
(Purchase order number) \\
May we make your name/address availabie to other mailers? $\begin{array}{c}\text { Yes No } \\
0\end{array}$
\end{tabular}

Please indicate method of payment

- Check payable to the Superintendent of Documents

GPO Deposit Account $\square\left[\begin{array}{lll}\hline & & \end{array}\right.$

$\square$ VISA, Choice, or MasterCard Account

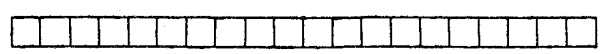

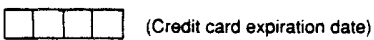

\begin{tabular}{ll}
\hline (Authorizing Signature) & $1 / 92$ \\
Thank you for \\
your order!
\end{tabular}

$\cdots$

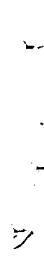

$=$

$\cdots$

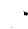

$\approx$

$\Rightarrow$

$-$

$\because$ 